\title{
A study of factors leading to osteo-penia in the community: BMD camp based approach
}

\author{
Santosh Kumar Mishra ${ }^{1}$, Anshuli Trivedi ${ }^{2 *}$, Anubhooti Trivedi ${ }^{3}$
}

\begin{abstract}
${ }^{1}$ Dept of Orthopaedics, Gandhi Medical College Hamidia Hospital, Barkatullah Univeristy, Bhopal, M.P., India ${ }^{2}$ Dept of Community Medicine, Gandhi Medical College, Hamidia Hospital Barkatullah Univeristy, M.P., India ${ }^{3}$ Medical Officer Saket Nursing Home, Jabalpur, M.P., India
\end{abstract}

Received: 01 May 2015

Revised: 12 May 2015

Accepted: 24 May 2015

\section{*Correspondence:}

Dr. Anshuli Trivedi,

E-mail: dranshulitrivedi@yahoo.com

Copyright: () the author(s), publisher and licensee Medip Academy. This is an open-access article distributed under the terms of the Creative Commons Attribution Non-Commercial License, which permits unrestricted non-commercial use, distribution, and reproduction in any medium, provided the original work is properly cited.

\section{ABSTRACT}

Background: Osteoporosis is an important public health problem in times of increasing life expectancy. A large number of cases are undiagnosed resulting in bone fragility \& fractures. Bone mineral density reduces physiological in both sexes, but it is more rampant in women in hypoandrogenic states, i.e. post menopause.

Methods: A community based bone mineral density estimation camp was organized in a private health facility catering to the urban community in Jabalpur district of M.P during February 2015. In the camp bone mass density of attendees was assessed using DEXA technique \& WHO criteria based on T score were used in the study to assess the bone mineral density. Information about social-demographic condition along with brief medical \& surgical history was elicited. The results were presented in terms of percentage \& proportions. The tests of significance were used for establishing associations between variables.

Results: In total 298 persons attended the camp. There is a statistically significant association between prevalence of decreased BMD with age $(\mathrm{p}<0.001)$. In total, $55.74 \%$ female attendees had T-score < -1.0 . Hysterectomiesed women had statistically significant lower mineral densities. There is a significant association between regular alcohol intake $\&$ decreased BMD as all the Osteoporotic men in the study had BMD $<-2.5$.

Conclusion: A camp based approach helps in identifying subclinical cases of Osteopenia in the community.

Keywords: Osteoporosis, Camp based approach, DEXA technique, T-score

\section{INTRODUCTION}

In today's times of increasing life expectancy there is an increase in prevalence of degenerative conditions like osteoporosis. Osteoporosis is a progressive bone disease that is characterized by a decrease in bone mass and density which can lead to an increased risk of fracture. ${ }^{1}$ In osteoporosis, the bone mineral density (BMD) is reduced, bone micro-architecture deteriorates, and the amount and variety of proteins in bone are altered. Osteoporosis is defined by WHO as a bone mineral density of $<2.5$ STDEV or more below the mean peak bone mass. ${ }^{2}$ In times of increased women empowerment where women are becoming bread earners, they are at par with men. There is a serious need to focus on their health. In Indian scenario women being involved in family life usually ignore their health resulting in decreased in bone densities. Also, as hormonal factors strongly influence the pace of bone resorption; lack of estrogen (e.g. As a result of menopause) increases bone resorption, as well as decreases the deposition of new bone that normally takes place in weight-bearing bones. ${ }^{3}$ Women are exposed to hypo-androgenic states following physiological menopause or early menopause following hysterectomy for some gynecological reasons. Females suffer from Type-1 or post menopausal osteoporosis, whereas type 2 or senile osteoporosis is common in both sexes after 75 years of age. ${ }^{4}$ As it is established that bone density decreases with age, more people become osteoporotic with increasing age. ${ }^{5}$ 
Osteoporosis is seldom diagnosed as it is usually symptomless. But its main consequence is the increased risk of bone fractures. There is increased bone fragility \& fractures occurring in conditions where healthy people would not normally suffer a fracture. Typical fragility fractures occur in the vertebral column, rib, hip and wrist. $^{3}$ Bone mineral density is diagnosed using Dualenergy X-ray absorptiometry (DXA) in which bone mineral density level is less than or equal to 2.5 standard deviations below that of a young (30-40 year old ${ }^{5,6}$, healthy adult women reference population. This is translated as a T-score. The study aims to understand social, demographic profile of attendees to assess awareness about the importance of BMD estimation for early diagnosis \& treatment of Osteopenia/porosis. It also aims to find correlates of various factors responsible for the decrease in BMD. A camp based approach is free of cost means of providing medical services to the community at their doorstep \& ensure their greater participation.

\section{METHODS}

A community based bone mineral density estimation camp was organized in a private health facility catering to the urban community in Jabalpur district of M.P during February 2015. In the camp bone mass density of attendees was assessed using DEXA technique in which thickness of the styloid process of the radius was measured. The WHO criteria based on T-score was used to study in which Normal Bone mineral density BMD Tscore was $\geq-1.0$. Osteopenia is $-2.5<\mathrm{T}$-score $<-1.0$, Osteoprosis is T-score $\leq-2.5 \&$ severe osteoporosis is a T-score $\leq-2.5$ with fragility fracture. ${ }^{2}$ The patient's socio demographic profile was recorded along with history of any chronic medical conditions or hypo-androgenic states were recorded using predesigned pretested proforma. Those consenting for inclusion in the study were interviewed \& their data was compiled \& analyzed by using MS-Excel-2007.The results were presented in terms of percentage \& proportions. The tests of significance were used for establishing associations between variables. The patients having T-score $<-1.0$ were given nutritional advice, calcium supplements \& were counseled for regular BMD assessment.

\section{RESULTS}

In total 298 persons attended the camp. Amongst attendees $39.59 \%$ attendees were osteo-penic/porotic. Of all attendees $36.91 \%$ were of $30-45$ years of age more than half were female attendees (Table 1). In total 38.09 $\%$ patients $>75$ years had $\mathrm{T}$-score $\leq-2.5$ (Osteoporosis). There is a statistically significant association between prevalence of decreased BMD with age $(\mathrm{p}<0.001)$ (Table 2 ). In total $51.34 \%$ attendees were females out of which $41.17 \%$ had score $-2.5<\mathrm{T}$-score $<-1.0$ (Osteopenia) \& $14.37 \%$ had $\mathrm{T}$-score <- 2.5 respectively (Table 1 ). In total 7 female attendees were hysterectomised out which $57.14 \%$ had $\mathrm{T}$-score <- 2.5. In general females had lower
BMD $\quad(\mathrm{p}<0.001) \quad \&$ hystrectomised women had statistically significant lower mineral densities than women who retained uterus (Table 2). In total $62.42 \%$ attendees were below poverty Line (BPL) \& $61.07 \%$ attendees were illiterate or informally educated (Table 1). In the study 19 male attendees were regular alcoholics \& consumed atleast $40 \mathrm{gm}$ of alcohol daily for at least past 3 years. There is a significant association between regular alcohol intake \& decreased BMD as all the Osteoporotic men in the study had BMD <-2.5 (Table 1).

Table 1: Demographic characteristics.

\begin{tabular}{|lcc|}
\hline $\begin{array}{l}\text { Distribution of attendees } \\
\text { on the basis of age }\end{array}$ & $\mathbf{N}$ & $\%$ \\
\hline$<30$ & 55 & 18.46 \\
\hline $30-45$ & 110 & 36.91 \\
\hline $46-60$ & 67 & 22.48 \\
\hline $61-75$ & 45 & 15.10 \\
\hline$>75$ & 21 & 7.05 \\
\hline Total & 298 & 100.00 \\
\hline Distribution of attendees on the basis of sex \\
\hline Male & 145 & 48.66 \\
\hline Female & 153 & 51.34 \\
\hline $\begin{array}{l}\text { Distribution of attendees on the basis of Socio economic } \\
\text { classification }\end{array}$ & \multicolumn{2}{l|}{} \\
\hline Below Poverty line & 186 & 62.42 \\
\hline Above poverty line & 112 & 37.58 \\
\hline Distribution of attendees on the basis of education \\
\hline Illiterate & 89 & 29.87 \\
\hline Informal education & 93 & 31.21 \\
\hline Upto class V & 44 & 14.77 \\
\hline V- VIII Class & 39 & 13.09 \\
\hline VIII-XII Class & 18 & 6.04 \\
\hline Graduate \& Post graduate & 15 & 5.03 \\
\hline
\end{tabular}

Table 2: Bone mineral density.

\begin{tabular}{|c|c|c|c|c|}
\hline & $\begin{array}{l}>\frac{-1}{\text { (Normal) }} \\
\text { Nor }\end{array}$ & $\begin{array}{l}-2.5<\mathrm{T}- \\
\text { score }<-1.0 \\
\text { (Osteopenia) }\end{array}$ & $\begin{array}{l}\text { T-score } \\
\leq-2.5 \\
\text { (Osteop } \\
\text { orosis) }\end{array}$ & Total \\
\hline \multicolumn{5}{|c|}{ Distribution of patients on the basis of T score \& Age } \\
\hline$<30$ & $\underline{46}$ & 9 & 0.00 & 55 \\
\hline $30-45$ & $\overline{85}$ & 24 & 1.00 & 110 \\
\hline $46-60$ & 35 & $\underline{30}$ & 2 & 67 \\
\hline $61-75$ & 10 & $\overline{22}$ & 13 & 45 \\
\hline \multirow[t]{2}{*}{$>75$} & 4 & 9 & 8 & 21 \\
\hline & 180 & 94 & 24 & 298 \\
\hline \multicolumn{5}{|c|}{ Chi sq-105.15 df-8 p-<0.0001 } \\
\hline \multicolumn{5}{|c|}{ Distribution of patients on the basis of sex \& T score } \\
\hline Males & 112 & 31 & 2 & 145 \\
\hline Females & 68 & 63 & 22 & 153 \\
\hline \multicolumn{5}{|c|}{ Chi sq-38.13 df-2 p-<0.0001 } \\
\hline \multicolumn{5}{|c|}{ Distribution of females on the basis of androgenic states } \\
\hline $\begin{array}{l}\text { Uterus } \\
\text { present }\end{array}$ & 99 & 45 & 2 & 146 \\
\hline
\end{tabular}




\begin{tabular}{|c|c|c|c|c|}
\hline $\begin{array}{l}\text { Uterus } \\
\text { removed }\end{array}$ & 1 & 2 & 4 & 7 \\
\hline \multicolumn{5}{|c|}{ Chi sq-55.92 df- 2 p-<0.0001 } \\
\hline \multicolumn{5}{|c|}{$\begin{array}{l}\text { Distribution of males on the basis of chronic alcohol } \\
\text { intake }\end{array}$} \\
\hline $\begin{array}{l}\text { Regular } \\
\text { alcohol } \\
\text { consump } \\
\text { tion }\end{array}$ & 9 & 8 & 2 & 19 \\
\hline $\begin{array}{l}\text { No } \\
\text { regular } \\
\text { alcohol } \\
\text { consump } \\
\text { tion }\end{array}$ & 103 & 23 & 0 & 126 \\
\hline Chi Sq-20 & $18 \mathrm{df}-$ & 0001 & & \\
\hline
\end{tabular}

\section{DISCUSSION}

As seen in the study that more than one third of community members were unaware of their reduced BMD. As it was their first BMD assessment in life time. It is seen that there is regular decrease in BMD with advancing age. It is expected that there will be a large section of the population with lower BMD as there is an increase in life expectancy due advent of newer preventive \& curative means. Due to this there is likely to increase in the elderly population and age-specific incidence of fractures, it is inevitable that the health burden due to fractures will increase. ${ }^{7}$ Also the female population is at greater risk of osteoporosis. It is also seen that Asian women are at greater risk of osteoporosis. Also hypoandrogenic states increased risk of fragile bones. ${ }^{8}$ This could be concluded from the fact that they have limited exposure to sunlight. A lot of emphasis is given to decrease BMD in women's health. In the study it was found that $55.7 \%$ females had T-score <-1.0. In absence of adequate preventive measure they are likely to develop weaker bones.

In the study it was found that $22.75 \%$ male attendees had T-score <-1.0. This is supported by study conducted by Mi Jin Kim et al., in Korea that osteoporosis in men is an important public health problem. ${ }^{7}$ There is neglect of assessing BMD for males as pathophysiology of males relating to osteoporosis remains to be fully elucidated. As methods for the diagnosis of male osteoporosis have not been established. ${ }^{7}$ Also the WHO criteria for females have, until now, been used to diagnose male osteoporosis. In the study it was found that there is a positive correlation of alcohol intake \& decreased BMD this is supported by Korean study that stated that chronic alcohol consumption induces low bone density. ${ }^{8}$ The community based health camps provide an opportunity for BMD assessment in as the camp was free of cost, an expensive investigation supplemented with dietary \& therapeutic consultation provided an opportunity for cognizing reducing BMD.

\section{CONCLUSION}

A camp based approach helps in identifying subclinical cases of Osteopenia in community. They can help in increasing awareness of skeletal health especially in developing countries where a large section of population cannot afford expensive investigation like BMD estimation. A community camp based approach has greater participation of women as their health is usually neglected in times of increased out of pocket expenditure on health.

\section{Limitations}

As it was a camp based study other investigations to confirm medical conditions could not be performed.

\section{Funding: No financial aid was received \\ Conflict of interest: None declared}

Ethical approval: Approved by the institutional ethics committee

\section{REFERENCES}

1. Alldredge BK, Koda-Kimble MA, Young LY, Kradjan WA, Guglielmo BJ. Applied therapeutics: the clinical use of drugs. Philadelphia: Wolters Kluwer Health/Lippincott Williams \& Wilkins. 2009; 101-103.

2. Assessment of fracture risk and its application to screening for postmenopausal osteoporosis. Report of a WHO Study Group". World Health Organization technical report series. 843:1-129.

3. Raisz L. Pathogenesis of osteoporosis: concepts, conflicts, and prospects. J Clin Invest. 2005;115(12):3318-25.

4. Osteoporosis from Wikipedia the free encyclopedia. http://en.wikipedia.org/wiki/Osteoporosis.

5. Prevention and management of osteoporosis: report of a WHO scientific group (PDF). WHO Scientific Group on the Prevention and Management of Osteoporosis (2000: Geneva, Switzerland), 2003. http://www.who.int/chp/topics/Osteoporosis.pdf

6. $\mathrm{Wu} \mathrm{S}$. Genome-wide approaches for identifying genetic risk factors for osteoporosis" Genome Med. 2013. doi:10.1186/gm448.

7. Mi Jin Kim MD, Myung Suk Shim MD et al. Effect of Chronic Alcohol Ingestion on Bone Mineral Density in Males without Liver Cirrhosis. Korean J Intern Med. 2003;18:174-80.

8. What Is Osteoporosis? Fast Facts: An Easy-to-Read Series of Publications for the Public. National Institute of Arthritis and Musculoskeletal and Skin Diseases.

http://www.niams.nih.gov/health_info/bone/osteopo rosis/osteoporosis_ff.asp recoverd on 25/04/15.

Cite this article as: Mishra SK, Trivedi A, Trivedi A. A study of factors leading to osteo-penia in the community: BMD camp based approach. Int $\mathrm{J}$ Community Med Public Health 2015;2(3):234-6. 